\title{
Transgenic expression of human matrix metalloproteinase-1 attenuates pulmonary arterial hypertension in mice
}

\author{
Joseph GEORGE ${ }^{1}$, Jie SUN, and Jeanine D'ARMIENTO \\ Division of Molecular Medicine, Department of Medicine, Columbia University, New York, NY \\ 10032, U.S.A
}

\begin{abstract}
PAH (pulmonary arterial hypertension) is a debilitating and life-threatening disease, often affecting young people. We specifically expressed human MMP-1 (matrix metalloproteinase-1) in mouse macrophages and examined its effects in attenuating the decompensating features of MCT (monocrotaline)-induced PAH. Measurement of RV (right ventricular) pressure revealed a 2.5fold increase after treatment with MCT, which was reduced to 1.5-fold in MMP-1 transgenic mice. There was conspicuous pulmonary inflammation with chronic infiltration of mononuclear cells after the administration of MCT, which was significantly diminished in transgenic mice. Furthermore, transgenic mice showed decreased collagen deposition compared with WT (wildtype). Staining for Mac-3 (macrophage-3) and $a$-SMA ( $a$-smooth muscle actin) revealed extensive infiltration of macrophages and medial hypertrophy of large pulmonary vessels with complete occlusion of small arteries respectively. These changes were markedly reduced in MMP-1 transgenic mice compared with WT. Western blotting for molecules involved in cell multiplication and proliferation depicted a significant decrease in the lung tissue of transgenic mice after the treatment with MCT. In conclusion, the present study demonstrated that transgenic expression of human MMP-1 decreased proliferation of smooth muscle cells and prevented excessive deposition of collagen in the pulmonary arterial tree. Our results indicate that upregulation of MMP-1 could attenuate the debilitation of human PAH and provide an option for therapeutic intervention.
\end{abstract}

\section{Keywords}

matrix metalloproteinase-1 (MMP-1) transgene; monocrotaline; occlusion; pulmonary arterial hypertension

\section{INTRODUCTION}

PAH (pulmonary arterial hypertension) is marked by a persistent elevation of pulmonary artery pressure with normal pressure in the left ventricle [1,2]. An elevation of mean pulmonary arterial pressure above $25 \mathrm{mmHg}$ at rest or $30 \mathrm{mmHg}$ with exercise is considered diagnostic for PAH. PAH is characterized by vasoconstriction, in situ thrombosis, intimal

\section{(C) 2012 Biochemical Society}

Correspondence: Dr Joseph George (joseph.george@mssm.edu or jgeorge40@hotmail.com).

${ }^{1}$ Present address: Division of Liver Diseases, Department of Medicine, Mount Sinai School of Medicine, 1425 Madison Avenue, New York, NY 10029, U.S.A.

\section{AUTHOR CONTRIBUTION}

Joseph George carried out most of the experiments, analysed the data, drew the conclusion and wrote the paper. Jie Sun contributed to the animal experiments and measured the RV pressure. Jeanine D'Armiento hypothesized/designed the study and obtained National Institutes of Health funding for the study. All the authors approved the manuscript for publication. 
lesions and hypertrophic remodelling of pulmonary arteries, inducing increased pulmonary arterial pressure $[3,4]$. Homoeostatic imbalances between vasodilators and vasoconstrictors, growth inhibitors and mitogenic factors and antithrombotic and prothrombotic determinants are the underlying pathogenetic mechanisms associated with PAH [5,6]. Furthermore, PAH is attributed to both the hypertrophy and hyperplasia of resident smooth muscle cells and increased depositions of extracellular matrix components that result in constriction of pulmonary vessels and increased mean arterial pressure $[7,8]$. The molecular mechanisms regulating collagen deposition during pathogenesis of PAH have been poorly understood.

It is unclear what are the cellular and molecular mechanisms underlying the transition from compensated hypertrophy to dilatation and failure that occurs during the pathogenesis of PAH. MMPs (matrix metalloproteinases) could play a significant role in the remodelling of vascular tissue during pathogenesis of PAH [8-10]. Marked increases in MMP-2 and MMP-9 (gelatinases) have been observed in pulmonary hypertension [11,12]. The upregulation of gelatinases in PAH contributes to the degradation of the adventitial extracellular matrix, which promotes proliferation and migration of vascular smooth muscle cells into small peripheral, normally non-muscular, pulmonary arteries within the respiratory acinus [13]. The complete cellular processes underlying the muscularization of the pulmonary arterial tree are not clear. This process is normally accompanied by the deposition of mature collagen fibres surrounding the small pulmonary arteries, which contribute to the constriction of pulmonary vessels and pathogenesis of PAH. The upregulation of TIMP-1 (tissue inhibitor of metalloproteinases-1) [14] in cigarette-smokeinduced vascular remodelling and pulmonary hypertension could inhibit interstitial collagenases, especially MMP-1, and promote the deposition of mature collagen fibres. We have demonstrated previously that transgenic expression of MMP-1 inhibits myocardial fibrosis and prevents transition to heart failure in a pressure overload mouse model [15]. Therefore we hypothesized that transgenic expression of MMP-1 could also prevent the deposition of mature collagen fibres surrounding the pulmonary vessels and protect against the pathogenesis of PAH.

MCT (monocrotaline)-induced PAH in rats is a well-studied model for human pulmonary hypertension [16-18]. However, transgenic and knockout studies are not feasible with rat models of PAH. We have established a murine model of PAH with the decompensating features of human pulmonary hypertension using serial administrations of MCT [19]. The pathogenesis of MCT-induced lung injury in mouse includes interstitial oedema, chronic infiltration of inflammatory cells, RV (right ventricular) hypertrophy, medial hypertrophy of the pulmonary arteries and a marked increase in mean pulmonary pressure. Even though the understanding of the pathogenesis of PAH has been considerably improved in recent years, further studies are necessary to unravel the molecular mechanism of pulmonary vascular remodelling and collagen deposition. The aim of the present study was to examine the role of macrophage-specific transgenic expression of human MMP-1 in the inhibition of MCTinduced PAH in mice.

\section{MATERIALS AND METHODS}

\section{Animals}

All animal experiments were carried out in accordance with the Guide for the Care and Use of Laboratory Animals published by the NIH (National Institutes of Health; NIH Publication No. 86-23, revised 1996) and also in compliance our Institutional Animal Care and Use Committee. 


\section{MMP-1 transgenic mice}

We generated and characterized the MMP-1 transgenic mouse in our laboratory and the same was described in detail previously [20]. In this mouse model, the human MMP-1 enzyme would specifically express in their macrophages. Mouse is an appropriate animal model to study the function of MMP-1 because the mouse does not contain a homologue of human MMP-1. Briefly, a 9.3 kb human genomic MMP-1 fragment was ligated downstream under the control of human SREP (scavenger receptor-enhancer promoter A) using an artificially created SmaI restriction site. An SmaI site, immediately preceding the translational initiation codon of the MMP-1 gene was introduced by in vitro mutagenesis. The SREP allows targeted expression of the MMP-1 gene specifically in differentiated macrophages of transgenic mice. The MMP-1 transgene was isolated from the plasmid vector by Not1/Sal1 restriction digestion, purified using caesium chloride density gradient centrifugation and microinjected into fertilized mouse eggs $(\mathrm{C} 57 \mathrm{BL} / 6 \mathrm{~J} \times \mathrm{CBA} / \mathrm{J}) \times(\mathrm{C} 57 \mathrm{BL} /$ $6 \mathrm{~J} \times \mathrm{CBA} / \mathrm{J})$ genetic background. The expression of the transgene was characterized in 3week-old pups by PCR analysis of the DNA obtained from the tail. Furthermore, a set of adult mice were killed and the expression of the transgene in the lung tissue was established through Western blotting [20]. Mice were then backcrossed into the C57BL/6J strain. Age matched littermates that do not express the transgene were used as control mice.

\section{Induction of PAH in the mouse}

We have successfully established a mouse model for PAH that depicts most decompensating features of human PAH [19]. MCT powder was procured from Sigma. It was dissolved in $0.1 \mathrm{M} \mathrm{HCl}$, neutralized with $0.1 \mathrm{M} \mathrm{NaOH}$ to $\mathrm{pH} 7.4$ and sterilized through a $0.22 \mu \mathrm{m}$ disc filter. Male mice at 3 months of age, weighing approx. $25 \mathrm{~g}$, were used for the studies. PAH was induced in both MMP-1 transgenic and their littermate WT (wild-type) mice with subcutaneous administrations of MCT in doses of $60 \mathrm{mg} / 100 \mathrm{~g}$ of body weight once a week for 8 consecutive weeks. The injections were given without anaesthesia. Control animals from both groups received similar injections (vehicle) without MCT. A total of six animals were used in each group. All animals were maintained with commercial mice feed and water available ad libitum. All the animals were killed on day 8 of the last MCT administration. We also had trial experiments in which we killed a few animals at early time points and evaluated the histopathological alterations including infiltration of macrophages.

\section{Measurement of RV pressure}

The RV systolic pressure, which represents mean pulmonary arterial pressure, was measured in WT and MMP-1 transgenic mice after the induction of PAH. All mice were anaesthetized with intraperitoneal injections of tribromoethanol (Avertin) at a dose of $0.15 \mathrm{ml} / 10 \mathrm{~g}$ of body weight and then ventilated (Harvard Apparatus) with airflow of $1 \mathrm{ml} / 100 \mathrm{~g}$ of body weight and a frequency of $60 \mathrm{~s}^{-1}$ after tracheotomy. Anaesthesia was maintained through inhalation of isoflurane. A superficial incision was made on the right ventral area of the neck and a portion of the right jugular vein was carefully exposed without bleeding. The distal portion of the jugular vein was ligated using a suture thread, and the proximal part was positioned with a small vessel clamp. A small incision was made on the jugular vein between the ligation and the vessel clamp and a 1.4F Millar Mikrotip catheter-transducer (model SPR-671; Millar Instruments) was inserted carefully. The catheter-transducer was secured with another suture thread and the vessel clamp was removed. Then the cathetertransducer was slowly inserted through the jugular vein, the right atrium and into the right ventricle. Progress of the catheter-transducer movement was monitored, and the pressure waveform was recorded using PowerLab (AD Instruments) after stabilization. 


\section{H/E (haematoxylin and eosin) and Masson's trichrome staining}

Histopathological evaluation of the pathogenesis of MCT-induced PAH and the effects of the human MMP-1 transgene were carried out through H/E and Masson's trichrome staining. The lungs were perfused with $3 \%$ (w/v) paraformaldehyde for $20 \mathrm{~min}$ and fixed in $10 \%$ phosphate buffered formalin. Two to three lobes of the lung tissue were embedded in paraffin blocks and sections of $8 \mu \mathrm{m}$ were cut. The tissue sections were stained for $\mathrm{H} / \mathrm{E}$ as per standard protocol. Masson's trichrome staining for collagen was carried out using a trichrome staining kit (Poly Scientific). The stained sections were examined using an Olympus microscope and photographed. Trichrome staining for collagen was quantified using Image-Pro discovery software (Media Cybernetics).

\section{Immunohistochemical staining for Mac-3 (macrophage-3) and $\alpha$-SMA ( $\alpha$-smooth muscle actin)}

Immunohistochemical staining for Mac-3 antigen and $a$-SMA filaments was carried out in paraffin-embedded lung tissue using a universal staining kit (Dako). The lung sections were deparaffinized using xylene and alcohol and hydrated. The sections were then treated with Mac-3 (BD Biosciences) and $a$-SMA (Invitrogen) primary antibodies and incubated in a moisturized chamber for $3-5 \mathrm{~h}$ at room temperature $\left(25^{\circ} \mathrm{C}\right)$. The sections were washed three times with ice-cold PBS and incubated with biotinylated anti-rabbit Ig and anti-mouse Ig for $30 \mathrm{~min}$. The slides were washed again and treated with HRP (horseradish peroxidase)labelled streptavidin and incubated for another $30 \mathrm{~min}$. The sections were again washed and treated with $3 \% 3$-amino-9-ethylcarbazole in $\mathrm{N}, \mathrm{N}$-dimethylformamide for $10 \mathrm{~min}$ for the development of brown colour. The stained sections were counterstained with Mayer's haematoxylin for $2 \mathrm{~min}$, treated with ammonia solution and mounted using an aqueousbased mounting medium. The slides were examined under a Nikon microscope equipped with a Spot RT Slider digital camera (Meyer Instruments) and photographed. The infiltrated macrophages in ten randomly selected microscopic fields and the staining intensity of $a$ SMA were quantified using Image-Pro discovery software (Media Cybernetics).

\section{Western blotting for molecules involved in cell proliferation}

Western blotting was carried out in the lung tissue for molecules related to cell proliferation in both WT and MMP-1 transgenic mice after treatment with MCT. Approximately $100 \mathrm{mg}$ of lung tissue was homogenized in $1 \mathrm{ml}$ of ice-cold $50 \mathrm{mM}$ Tris/ $\mathrm{HCl}$ buffer $(\mathrm{pH} 8)$ containing $150 \mathrm{mM} \mathrm{NaCl}, 1 \mathrm{mM}$ EDTA and $1 \%$ Triton X-100. The protease inhibitors 0.5 $\mathrm{mM}$ PMSF, $5 \mu \mathrm{g} / \mathrm{ml}$ aprotinin and $1 \mu \mathrm{g} / \mathrm{ml}$ pepstatin were added to the buffer immediately before use. The homogenate was centrifuged at $10000 \mathrm{~g}$ for $10 \mathrm{~min}$ at $4{ }^{\circ} \mathrm{C}$ and the supernatant was collected. The protein concentration in the supernatant was determined using the Coomassie Blue plus protein assay (Pierce Biotechnology), and the samples were stored at $-20{ }^{\circ} \mathrm{C}$ until they were assayed. The proteins were resolved on SDS/4-20\% polyacrylamide gradient gels (Bio-Rad) and electroblotted on to an activated PVDF membrane (Millipore). Non-specific binding sites were blocked with $5 \%$ milk, and the membranes were incubated overnight on a rocker at $4^{\circ} \mathrm{C}$ with specific antibodies. The antibodies for PCNA (proliferating-cell nuclear antigen) and CD31 were from BD Biosciences, FGF2 (fibroblast growth factor-2) antibody was from Santa Cruz and the antibody for MMP-9 was from Cell Signaling Technology. After incubation, the membranes were washed three times and treated with HRP-conjugated respective secondary antibodies (Biomeda) at room temperature for $2 \mathrm{~h}$. The membranes were washed again, treated with $\mathrm{ECL}^{\circledR}$ reagent (GE Healthcare), exposed to a Kodak autoradiography film (BioMax XAR) and developed. The membranes were re-probed using Western re-probe buffer (Gbiosciences) for GAPDH (glyceraldehyde-3-phosphate dehydrogenase) content with a monoclonal antibody (Novus Biologicals) to demonstrate that equal amounts of protein had 
been loaded in each lane. The Western blotting images were quantified using Gel-Pro analyser software (Media Cybernetics).

\section{Statistical analysis}

Means and S.D. were calculated for all quantitative measurements. The results were statistically evaluated using two-way ANOVA and were compared using the least significant difference method. $P<0.05$ was considered statistically significant.

\section{RESULTS}

\section{Evaluation of MCT-induced PAH}

The pathophysiological and histopathological alterations associated with MCT-induced PAH were evaluated through measurement of systolic RV pressure, H/E and Masson's trichrome staining, as well as immunohistochemical studies. Figure 1(A) demonstrates measurements of systolic RV pressure in WT and MMP-1 transgenic mice after the induction of PAH. The mean RV pressure was elevated from 25 to $60 \mathrm{mmHg}$ (2.5-fold) in MCT-treated WT mice. At the same time, the RV pressure in MCT-treated MMP-1 transgenic mice was elevated only up to $40 \mathrm{mmHg}$, which is significantly $(P<0.001)$ less than the RV pressure in MCT-treated WT mice. There was no alteration in the RV pressure in untreated MMP-1 transgenic mice compared with the WT control. Figure 1(B) shows the mean value of $\mathrm{RV}$ pressure measured in six animals in each group. The elevated $\mathrm{RV}$ pressures were significantly higher $(P<0.001$ and $P<0.01$ respectively) in the MCT-treated WT and MMP-1 transgenic mice compared with their respective untreated controls. However, the RV pressure was significantly lower $(P<0.001)$ in MCT-treated MMP-1 transgenic mice compared with MCT-treated WT mice.

\section{MMP-1 transgenic mice retained normal vasculature}

Figure 2 presents the results of H/E staining after the induction of PAH in WT and MMP-1 transgenic mice. Figure 2(A) shows the regular architecture of the lung tissue in untreated WT mice. There was no alteration in the lung tissue of MMP-1 transgenic mice (Figure 2B). Serial administrations of MCT resulted in hyperplasia of pulmonary vessels and intense infiltration of chronic inflammatory cells and macrophages in WT mice (Figure 2C). However, in MCT-treated MMP-1 transgenic mice, the histopathological alterations were minimal and the normal architecture of the pulmonary vessels was almost retained (Figure 2D). Figure 2(E) is a quantitative representation of the infiltrated neutrophils in the lung tissue after induction of PAH using MCT. The number of infiltrated neutrophils was significantly $(P<0.001)$ higher in MCT-treated WT and MMP-1 transgenic mice compared with their respective untreated controls. However, the number of neutrophils was significantly lower $(P<0.001)$ in MCT-treated MMP-1 transgenic mice compared with MCT-treated WT mice (Figure 2E).

\section{MMP-1 transgenic mice had decreased alveolar infiltration of macrophages}

The $110 \mathrm{kDa}$ Mac-3 antigen is a unique marker for mouse phagocytic macrophages. We monitored the infiltration of macrophages during MCT administration in order to assess the pulmonary inflammatory status which contributes to the pathogenesis of PAH. Staining for Mac-3 in WT and MMP-1 transgenic mice with and without MCT treatment is presented in Figure 3. Mac-3 staining was absent in the lung tissue of WT and MMP-1 transgenic control mice, indicating the absence of macrophage infiltration at the final stage of the study (Figures 3A and 3B). There was a marked infiltration of macrophages in both WT (Figure 3C) and MMP-1 transgenic mice (Figure 3D) killed on day 15, indicating infiltration of macrophages in MMP-1 transgenic mice on a par with the WT mice during the early periods 
of the study. MMP-1 gene is expressed in macrophages and infiltration of macrophages into the lung tissue contributes to the synthesis and release of active MMP-1 enzyme in the areas of inflammation. At the end of the study, large numbers of Mac-3-positive mononuclear cells were present in the lung tissue of WT mice treated with MCT, indicating intense infiltration of macrophages (Figure 3E). The infiltration of Mac-3-positive macrophages was significantly reduced in the lung tissue of MMP-1 transgenic mice examined at the end point (Figure 3F). Figure $3(\mathrm{G})$ is a quantitative representation of the infiltrated macrophages in the lung tissue after induction of PAH using MCT. The number of infiltrated macrophages was significantly $(P<0.001)$ higher in MCT-treated WT and MMP-1 transgenic mice compared with their respective untreated controls. However, the number of macrophages was significantly lower $(P<0.001)$ in MCT-treated MMP-1 transgenic mice compared with MCT-treated WT mice (Figure 3G).

\section{MMP-1 transgene prevented excessive collagen deposition}

Figure 4 demonstrates Masson's trichrome staining for mature collagen fibres (stained in blue) surrounding pulmonary vessels after the induction of PAH. The staining for collagen was absent in the pulmonary vessels of untreated WT and MMP-1 transgenic mice (Figures 4A and 4B). Excessive deposition of mature collagen fibres surrounding pulmonary vessels was present in WT mice treated with MCT (Figure 4C). There was medial hyperplasia with marked constriction of pulmonary vessels. The deposition of mature collagen fibres was minimal in MMP-1 transgenic mice treated with MCT (Figure 4D). Figure 4(E) shows quantitative representation of the staining intensity of collagen fibres in untreated controls and MCT-treated WT and MMP-1 transgenic mice. The collagen staining intensity was significantly $(P<0.001)$ higher in MCT-treated WT and MMP-1 transgenic mice compared with their respective untreated controls. The collagen staining intensity was significantly less $(P<0.001)$ in MCT-treated transgenic mice compared with similarly treated WT mice (Figure 4E).

\section{MMP-1 transgene prevented medial hyperplasia}

Immunohistochemical staining for $a$-SMA demonstrated thickening of smooth muscle cell wall and medial hypertrophy of pulmonary vessels after the administration of MCT (Figure 5). In both WT and MMP-1 transgenic untreated mice, $a$-SMA staining was weak, depicting normal pulmonary vessels (Figures 5A and 5B). Staining of $a$-SMA demonstrated medial hyperplasia and thickening of large pulmonary vessels as well as muscularization and marked constriction of distal precapillary arteries (centre) in WT mice after treatment with MCT (Figure 5C). There was progressive thickening of the wall of more proximal intraacinar and pre-acinar muscular arteries with almost complete closure of small vessels. However, these changes were significantly reduced in MCT-treated MMP-1 transgenic mice, with only moderate thickening of smooth muscle cell wall around the pulmonary arteries (Figure 5D). Quantitative evaluation of the staining intensity of smooth muscle cells depicted a significant decrease $(P<0.001)$ of $a$-SMA staining in MCT-treated MMP-1 transgenic mice compared with MCT-treated WT mice (Figure 5E).

\section{MMP-1 transgene decreased the expression of molecules involved in cell proliferation}

In an attempt to unravel the mechanism of decreased proliferation of smooth muscle cells and reduced PAH in MCT-treated MMP-1 transgenic mice, we determined the protein levels of the prominent molecules related to cell proliferation. All the molecules studied, namely, PCNA, MMP-9, CD31 and FGF2, were significantly elevated $(P<0.001)$ in MCTadministered WT mice (Figure 6A). The nuclear antigen PCNA is a major marker for cell multiplication and proliferation. MMP-9 paves the way for smooth muscle cell proliferation through degradation of the extracellular matrix, but not the fibrillar collagen. We observed a significant decrease $(P<0.001)$ of PCNA and MMP-9 in MCT-treated transgenic mice 
compared with similarly treated WT mice (Figure 6A). CD31 is the major endothelial cell marker and FGF2 plays a key role in endothelial cell proliferation and angiogenesis. Furthermore, FGF2 is also a potent vascular smooth muscle cell mitogen. Both these molecules were markedly decreased $(P<0.001)$ in MCT-administered MMP-1 transgenic mice compared with MCT-treated WT mice (Figure 6A). Reprobing of GAPDH demonstrated equal loading of proteins in all lanes. Figure 6(B) depicts a quantitative representation of the percentage alteration of proteins involved in cell proliferation. Among all the four molecules studied, the maximum elevation (3.12-fold) was observed in the case of FGF2 in MCT-treated WT mice.

\section{DISCUSSION}

In the present study, we demonstrated that transgenic expression of MMP-1 attenuates experimentally induced PAH in a mouse model. We have previously developed a successful mouse model for PAH that exhibits most of the decompensating features of human pulmonary hypertension [19]. Even though the causes for PAH may vary, the hallmark of all PAH is the elevation of pulmonary arterial pressure. Adventitial thickening of the pulmonary vessel wall, vasoconstriction of pulmonary arteries and chronic thrombosis contribute to increased pulmonary vascular resistance [21]. In the present study, there was a 2.5-fold increase in pulmonary arterial pressure in MCT-treated WT mice, which was significantly reduced in MMP-1 transgenic mice.

MMPs are a family of zinc-containing endopeptidases that play a key role in remodelling the connective tissue matrix in both physiology and pathology [22,23]. The overexpression of interstitial collagenases such as MMP-1 can degrade native fibrillar collagen and lead to degradation of extracellular matrix proteins in vivo. The extensive proliferation of vascular smooth muscle cells during the pathogenesis of PAH results in the synthesis and deposition of interstitial collagens surrounding the pulmonary vessels that contributes to medial hypertrophy [8,24]. This process leads to vasoconstriction and a decrease in blood flow, contributing to the pathogenesis of PAH. In the present study, we have observed a significant decrease in the deposition of collagen in MCT-treated transgenic mice compared with similarly treated WT mice. The overexpression of MMP-1 prevented the deposition of collagen surrounding pulmonary arteries and attenuated the pathogenesis of MCT-induced $\mathrm{PAH}$ in mice.

The pathogenesis of PAH is a dynamic and complex process that includes TGF- $\beta 1$ (transforming growth factor- $\beta 1$ ) signalling, oxidative stress, inflammation and extracellular matrix remodelling [25]. It comprises both genetic and environmental factors that result in a cascade of events characterized by vascular scarring, endothelial cell dysfunction and vascular smooth muscle proliferation [26]. Chronic infiltration of mononuclear cells and macrophages contributes to this process. In the present study, we have observed infiltration of mononuclear cells and Mac-3-positive macrophages after treatment with MCT. However, these processes were reduced in MMP-1 transgenic mice in later stages. In this study, we have expressed the human MMP-1 gene in macrophages. Infiltration of macrophages into the lung tissue after treatment with MCT contributes to the synthesis and release of active MMP-1 enzyme in the areas of inflammation. We have observed an extensive infiltration of macrophages in MMP-1 transgenic mice on a par with the WT mice in the first 2 weeks of MCT administration (Figures 3C and 3D). Since MMP-1 is mainly responsible for cleavage of major fibrillar collagens, extensive infiltration of macrophages in the early stages of MCT treatment in transgenic mice contributes to the production of MMP- 1 and eventually it is responsible for the degradation of fibrillar collagens. These processes could be responsible for reduced inflammation, decreased fibrosis and attenuation of PAH in transgenic mice. This could also explain a significant decrease in the infiltration of macrophages in MMP-1 
transgenic mice in later stages of the study. However, it would be noted that the infiltration of macrophages is still significantly high in transgenic mice compared with the respective untreated controls at the end of the study contributing to continued production of MMP-1.

Aberrant proliferation of vascular smooth muscle cells and enhanced remodelling of pulmonary arteries are two primary features of PAH [27]. The normally non-muscular peripheral arteries become muscular through differentiation of smooth muscle cells from precursor cells, pericytes and intermediate cells to mature $a$-SMA-positive smooth muscle cells [28]. In the present study, we have observed marked differentiation and proliferation of vascular smooth muscle cells, deposition of collagen and marked constriction of small pulmonary arteries. However, these changes were decreased in MMP-1 transgenic mice compared with the similarly treated WT mice, indicating that MMP-1 overexpression could protect against the debilitating effects of PAH. The exact molecular mechanism of differentiation and proliferation of vascular smooth muscle cells during pathogenesis of PAH is not known. It has been observed that pulmonary arterial smooth muscle cells from patients with primary pulmonary hypertension exhibit abnormal growth responses to TGF$\beta 1$ and bone morphogenetic proteins [29]. Furthermore, increased levels of FGF2 observed in MCT-treated WT mice could serve as a potent mitogen for vascular smooth muscle cells.

The nuclear antigen PCNA is up-regulated in the nuclei of cells during DNA synthesis and is considered as a marker for cell proliferation and multiplication. Increased expression of PCNA has been observed in the lung tissue of rats with MCT-induced PAH [30,31]. In the present study, we observed increased protein levels of PCNA, indicating enhanced DNA synthesis. The elevated PCNA levels reported in previous studies of the MCT-induced model of PAH as well as in the present study could be positively associated with vascular smooth muscle cell multiplication and proliferation. Furthermore, the increased PCNA and CD31 levels could also be attributed to proliferation of endothelial cells that contributes to intimal thickening. FGF2 plays a key role in endothelial cell proliferation and angiogenesis and also serves as a potent vascular smooth muscle cell mitogen [32]. Elevated levels of FGF2 were observed in patients with PAH and were suggested as a mitogenic factor in the proliferation of endothelial and smooth muscle cells in PAH [33]. The significant increase in FGF2 protein levels observed in MCT-treated WT mice in the present study may be directly related to the marked proliferation of smooth muscle cells and medial hyperplasia.

Vascular remodelling in PAH involves hyperproliferative and apoptosis-resistant pulmonary vascular endothelial cells [34]. Whereas abnormal proliferation of vascular smooth muscle cells mainly contributes to the adventitial thickening of pulmonary arteries, endothelial cell proliferation contributes to the intimal thickening. The elevated FGF2 levels observed in the present study could contribute to endothelial cell proliferation and intimal thickening, which is supported by the increased CD31 protein levels observed in the present study. The staining for vascular smooth muscle cells and CD31 protein levels were significantly reduced in MCT-treated MMP-1 transgenic mice compared with the similarly treated WT mice, indicating the protective effect of the MMP-1 transgene during the pathogenesis of PAH.

In conclusion, the present study demonstrates that MMP-1 plays a significant role in subsiding MCT-induced PAH in mice, and methods to up-regulate the levels of MMP-1 in PAH could attenuate the debilitation associated with human PAH and provide an option for therapeutic intervention.

\section{Acknowledgments}

FUNDING 
This work was supported by the National Institutes of Health [grant number HL086936 (to J.D’A.)].

\section{Abbreviations}

$\begin{array}{ll}\boldsymbol{a} \text {-SMA } & \boldsymbol{a} \text {-smooth muscle actin } \\ \text { CD31 } & \text { cluster of differentiation-31 } \\ \text { FGF2 } & \text { fibroblast growth factor-2 } \\ \text { GAPDH } & \text { glyceraldehyde-3-phosphate dehydrogenase } \\ \text { H/E } & \text { haematoxylin and eosin } \\ \text { HRP } & \text { horseradish peroxidase } \\ \text { Mac-3 } & \text { macrophage-3 } \\ \text { MCT } & \text { monocrotaline } \\ \text { MMP } & \text { matrix metalloproteinase } \\ \text { PAH } & \text { pulmonary arterial hypertension } \\ \text { PCNA } & \text { proliferating-cell nuclear antigen } \\ \text { RV } & \text { right ventricular } \\ \text { SREP } & \text { scavenger receptor-enhancer promoter } \\ \text { TGF- } \beta \text { 1 } & \text { transforming growth factor- } \beta 1 \\ \text { WT } & \text { wild-type }\end{array}$

\section{References}

1. Lykouras D, Sampsonas F, Kaparianos A, Efremidis G, Karkoulias K, Tsoukalas G, Spiropoulos K. Pulmonary arterial hypertension: need to treat. Inflamm Allergy Drug Targets. 2008; 7:260-269. [PubMed: 19075794]

2. Raiesdana A, Loscalzo J. Pulmonary arterial hypertension. Ann Med. 2006; 38:95-110. [PubMed: 16581695]

3. Boutet K, Montani D, Jaïs X, Yaïci A, Sitbon O, Simonneau G, Humbert M. Therapeutic advances in pulmonary arterial hypertension. Ther Adv Respir Dis. 2008; 2:249-265. [PubMed: 19124376]

4. Davies RJ, Morrell NW. Molecular mechanisms of pulmonary arterial hypertension: role of mutations in the bone morphogenetic protein type II receptor. Chest. 2008; 134:1271-1277. [PubMed: 19059957]

5. Tuder RM, Marecki JC, Richter A, Fijalkowska I, Flores S. Pathology of pulmonary hypertension. Clin Chest Med. 2007; 28:23-42. [PubMed: 17338926]

6. Rabinovitch M. Molecular pathogenesis of pulmonary arterial hypertension. J Clin Invest. 2008; 118:2372-2379. [PubMed: 18596905]

7. Farber HW, Loscalzo J. Pulmonary arterial hypertension. N Engl J Med. 2004; 351:1655-1665. [PubMed: 15483284]

8. Novotná J, Herget J. Possible role of matrix metalloproteinases in reconstruction of peripheral pulmonary arteries induced by hypoxia. Physiol Res. 2002; 51:323-334. [PubMed: 12449429]

9. Humbert M, Morrell NW, Archer SL, Stenmark KR, MacLean MR, Lang IM, Christman BW, Weir EK, Eickelberg O, Voelkel NF, Rabinovitch M. Cellular and molecular pathobiology of pulmonary arterial hypertension. J Am Coll Cardiol. 2004; 43:13S-24S. [PubMed: 15194174]

10. Perros F, Dorfmüller P, Humbert M. Current insights on the pathogenesis of pulmonary arterial hypertension. Semin Respir Crit Care Med. 2005; 26:355-364. [PubMed: 16121311] 
11. Frisdal E, Gest V, Vieillard-Baron A, Levame M, Lepetit H, Eddahibi S, Lafuma C, Harf A, Adnot S, Dortho MP. Gelatinase expression in pulmonary arteries during experimental pulmonary hypertension. Eur Respir J. 2001; 18:838-845. [PubMed: 11757635]

12. Zaidi SH, You XM, Ciura S, Husain M, Rabinovitch M. Overexpression of the serine elastase inhibitor elafin protects transgenic mice from hypoxic pulmonary hypertension. Circulation. 2002; 105:516-521. [PubMed: 11815437]

13. Tajsic T, Morrell NW. Smooth muscle cell hypertrophy, proliferation, migration and apoptosis in pulmonary hypertension. Compr Physiol. 2011; 1:295-317. [PubMed: 23737174]

14. Wright JL, Tai H, Wang R, Wang X, Churg A. Cigarette smoke upregulates pulmonary vascular matrix metalloproteinases via TNF- $a$ signaling. Am J Physiol Lung Cell Mol Physiol. 2007; 292:L125-L133. [PubMed: 16905636]

15. Foronjy RF, Sun J, Lemaitre V, D’Armiento JM. Transgenic expression of matrix metalloproteinase-1 inhibits myocardial fibrosis and prevents the transition to heart failure in a pressure overload mouse model. Hypertens Res. 2008; 31:725-735. [PubMed: 18633185]

16. Satoh M, Satoh A. 3-Hydroxy-3-methylglutaryl (HMG)-COA reductase inhibitors and phosphodiesterase type $\mathrm{V}$ inhibitors attenuate right ventricular pressure and remodeling in a rat model of pulmonary hypertension. J Pharm Pharm Sci. 2009; 11:118s-130s. [PubMed: 19203474]

17. Kolettis T, Vlahos AP, Louka M, Hatzistergos KE, Baltogiannis GG, Agelaki MM, Mitsi A, Malamou-Mitsi V. Characterisation of a rat model of pulmonary arterial hypertension. Hellenic J Cardiol. 2007; 48:206-210. [PubMed: 17715611]

18. Zhao YD, Courtman DW, Deng Y, Kugathasan L, Zhang Q, Stewart DJ. Rescue of monocrotalineinduced pulmonary arterial hypertension using bone marrow-derived endothelial-like progenitor cells: efficacy of combined cell and eNOS gene therapy in established disease. Circ Res. 2005; 96:442-450. [PubMed: 15692087]

19. George J, D'Armiento J. Transgenic expression of human matrix metalloproteinase-9 augments monocrotaline-induced pulmonary arterial hypertension in mice. J Hypertens. 2011; 29:299-308. [PubMed: 21063214]

20. Lemaître V, O’Byrne TK, Borczuk AC, Okada Y, Tall AR, D’Armiento J. ApoE knockout mice expressing human matrix metalloproteinase-1 in macrophages have less advanced atherosclerosis. J Clin Invest. 2001; 107:1227-1234. [PubMed: 11375412]

21. Voelkel, NF.; Tuder, RM.; Weir, EK. Pathophysiology of primary pulmonary hypertension. In: Rubin, L.; Rich, S., editors. Primary Pulmonary Hypertension. Marcel Dekker; New York: 1997. p. 83-129.

22. Pardo A, Selman M. MMP-1: the elder of the family. Int J Biochem Cell Biol. 2005; 37:283-288. [PubMed: 15474975]

23. Ohbayashi H. Matrix metalloproteinases in lung diseases. Curr Protein Pept Sci. 2002; 3:409-421. [PubMed: 12370004]

24. Lepetit H, Eddahibi S, Fadel E, Frisdal E, Munaut C, Noel A, Humbert M, Adnot S, D’Ortho MP, Lafuma C. Smooth muscle cell matrix metalloproteinases in idiopathic pulmonary arterial hypertension. Eur Respir J. 2005; 25:834-842. [PubMed: 15863640]

25. Csiszar A, Labinskyy N, Jo H, Ballabh P, Ungvari Z. Differential proinflammatory and prooxidant effects of bone morphogenetic protein-4 in coronary and pulmonary arterial endothelial cells. Am J Physiol Heart Circ Physiol. 2008; 295:H569-H577. [PubMed: 18539760]

26. Humbert M, Montani D, Perros F, Dorfmüller P, Adnot S, Eddahibi S. Endothelial cell dysfunction and cross talk between endothelium and smooth muscle cells in pulmonary arterial hypertension. Vasc Pharmacol. 2008; 49:113-118.

27. Jeffery TK, Morrell NW. Molecular and cellular basis of pulmonary vascular remodeling in pulmonary hypertension. Prog Cardiovasc Dis. 2002; 45:173-202. [PubMed: 12525995]

28. Rabinovitch M. Pathobiology of pulmonary hypertension. Annu Rev Pathol Mech Dis. 2007; 2:369-399.

29. Morrell NW, Yang X, Upton PD, Jourdan KB, Morgan N, Sheares KK, Trembath RC. Altered growth responses of pulmonary artery smooth muscle cells from patients with primary pulmonary hypertension to transforming growth factor- $\beta 1$ and bone morphogenetic proteins. Circulation. 2001; 104:790-795. [PubMed: 11502704] 
30. Lee DS, Kim YK, Jung YW. Simvastatin, sildenafil and their combination in monocrotaline induced pulmonary arterial hypertension. Korean Circ J. 2010; 40:659-664. [PubMed: 21267389]

31. Hongo M, Mawatari E, Sakai A, Ruan Z, Koizumi T, Terasawa F, Yazaki Y, Kinoshita O, Ikeda U, Shibamoto T. Effects of nicorandil on monocrotaline-induced pulmonary arterial hypertension in rats. J Cardiovasc Pharmacol. 2005; 46:452-458. [PubMed: 16160596]

32. Chen CH, Poucher SM, Lu J, Henry PD. Fibroblast growth factor 2: from laboratory evidence to clinical application. Curr Vasc Pharmacol. 2004; 2:33-43. [PubMed: 15320831]

33. Benisty JI, McLaughlin VV, Landzberg MJ, Rich JD, Newburger JW, Rich S, Folkman J. Elevated basic fibroblast growth factor levels in patients with pulmonary arterial hypertension. Chest. 2004; 126:1255-1261. [PubMed: 15486390]

34. Asosingh K, Aldred MA, Vasanji A, Drazba J, Sharp J, Farver C, Comhair SA, Xu W, Licina L, Huang L, et al. Circulating angiogenic precursors in idiopathic pulmonary arterial hypertension. Am J Pathol. 2008; 172:615-627. [PubMed: 18258847] 

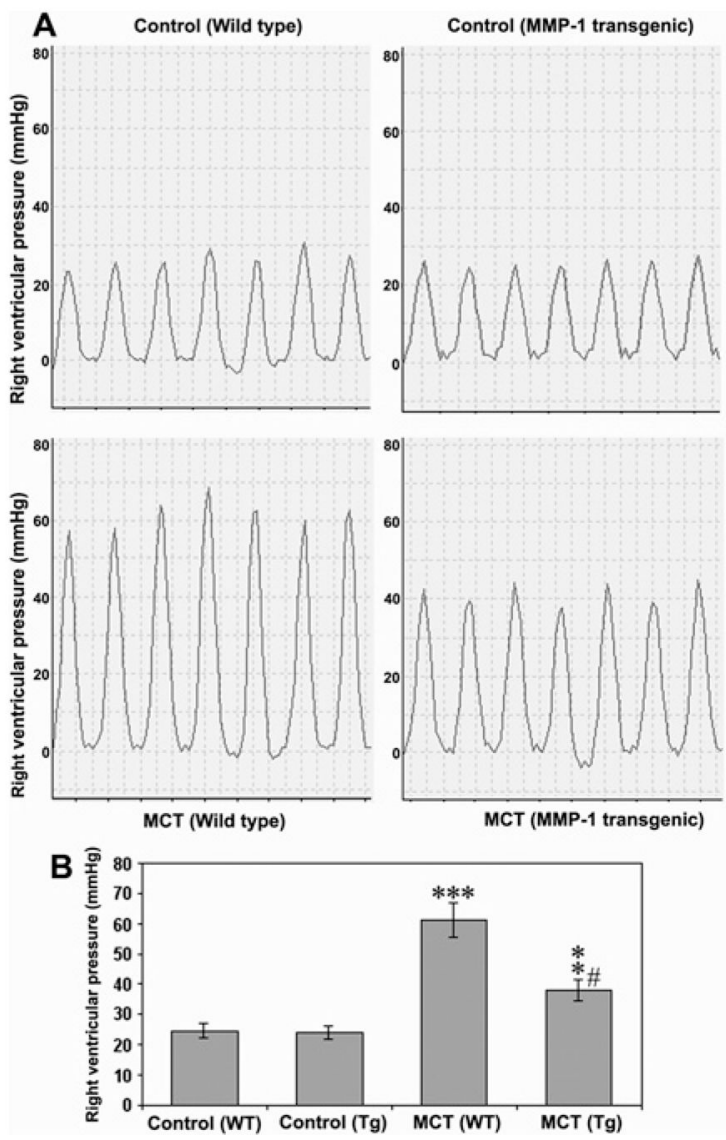

Figure 1. RV systolic pressure after the induction of PAH using MCT in WT and MMP-1 transgenic mice

(A) Measurements of RV systolic pressure after the induction of PAH using MCT in WT and MMP-1 transgenic mice. RV pressure was measured using a 1.4F Millar Mikrotip catheter-transducer inserted through the right jugular vein into the right atrium and then into the right ventricle. MCT-induced PAH resulted in a 2.5-fold increase of RV pressure in WT mice, which was significantly reduced in MMP-1 transgenic mice. The results are representative of six animals in each group. (B) Quantitative representation of systolic RV pressure in WT and MMP-1 transgenic mice after the induction of PAH. The results are the means \pm S.D. for six animals in each group $\left({ }^{* *} P<0.01\right.$ and ${ }^{* * *} P<0.001$ compared with the respective untreated controls and ${ }^{\#} P<0.001$ compared with the MCT-treated WT). 


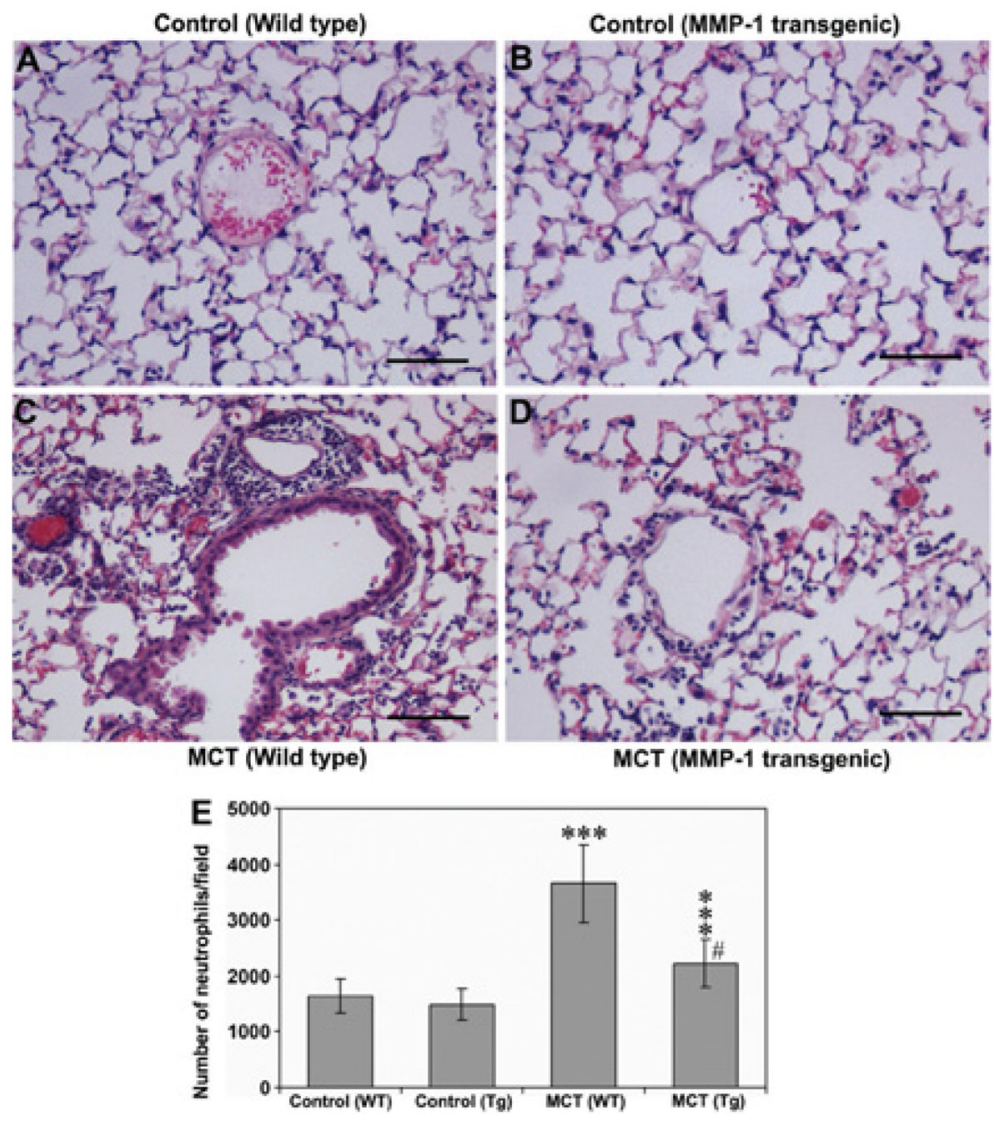

Figure 2. H/E staining of lung tissue in WT and MMP-1 transgenic mice after the induction of PAH using MCT

The results are representative of six animals in each group. (A) Normal lung WT mice $(\times 100)$. (B) MMP-1 transgenic mice $(\times 100)$. (C) WT mice $(\times 100)$. MCT was administered in doses of $60 \mathrm{mg} / 100 \mathrm{~g}$ of body weight once a week for 8 consecutive weeks. Loss of normal architecture of alveoli, and intense infiltration of chronic inflammatory cells and macrophages were observed. (D) MCT-administered MMP-1 transgenic mice $(\times 100)$. Only moderate infiltration of inflammatory cells were present. Scale bars, $100 \mu \mathrm{m}$. (E)

Quantitative representation of the infiltration of neutrophils. The number of neutrophils in ten randomly selected microscopy fields was quantified. The results are the means \pm S.D. for six animals in each group $\left({ }^{* * *} P<0.001\right.$ compared with the respective untreated controls and $\# P<0.001$ compared with the MCT-treated WT). Tg, transgenic. 

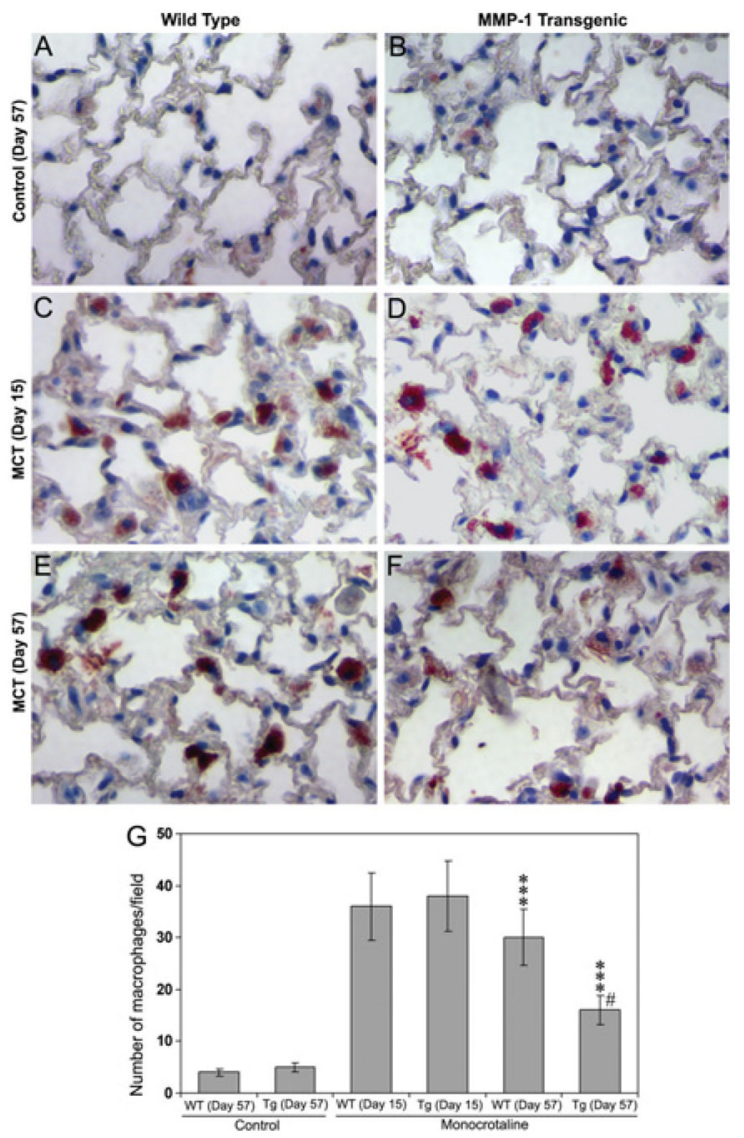

Figure 3. Immunohistochemical staining for macrophages in the lung tissue of WT and MMP-1 transgenic mice after the induction of PAH using MCT

The results presented are representative of six animals in each group. (A) Normal lung WT mice $(\times 200)$. Macrophages were absent. (B) MMP-1 transgenic mice $(\times 200)$. Macrophages were absent. (C) MCT-administered WT mice on day $15(\times 200)$. Marked infiltration of macrophages was observed. (D) MCT-administered MMP-1 transgenic mice on day 15 ( $\times 200)$. Marked infiltration of macrophages on a par with the WT mice was observed. (E) MCT-administered WT mice $(\times 200)$. Extensive infiltration of macrophages was observed. (F) MCT-administered MMP-1 transgenic mice $(\times 200)$. The infiltration of macrophages that expresses MMP-1 gene was significantly reduced in later stages of the study compared with the macrophages that do not express MMP-1 gene in WT mice. (G) Quantitative representation of the infiltration of macrophages. The number of macrophages in ten randomly selected microscopic fields was quantified using Image-Pro discovery software. The results are the means \pm S.D. for six samples $\left({ }^{* * *} P<0.001\right.$ compared with the respective untreated controls, and ${ }^{\#} P<0.001$ compared with MCT-treated WT on day 57). Tg, transgenic. 


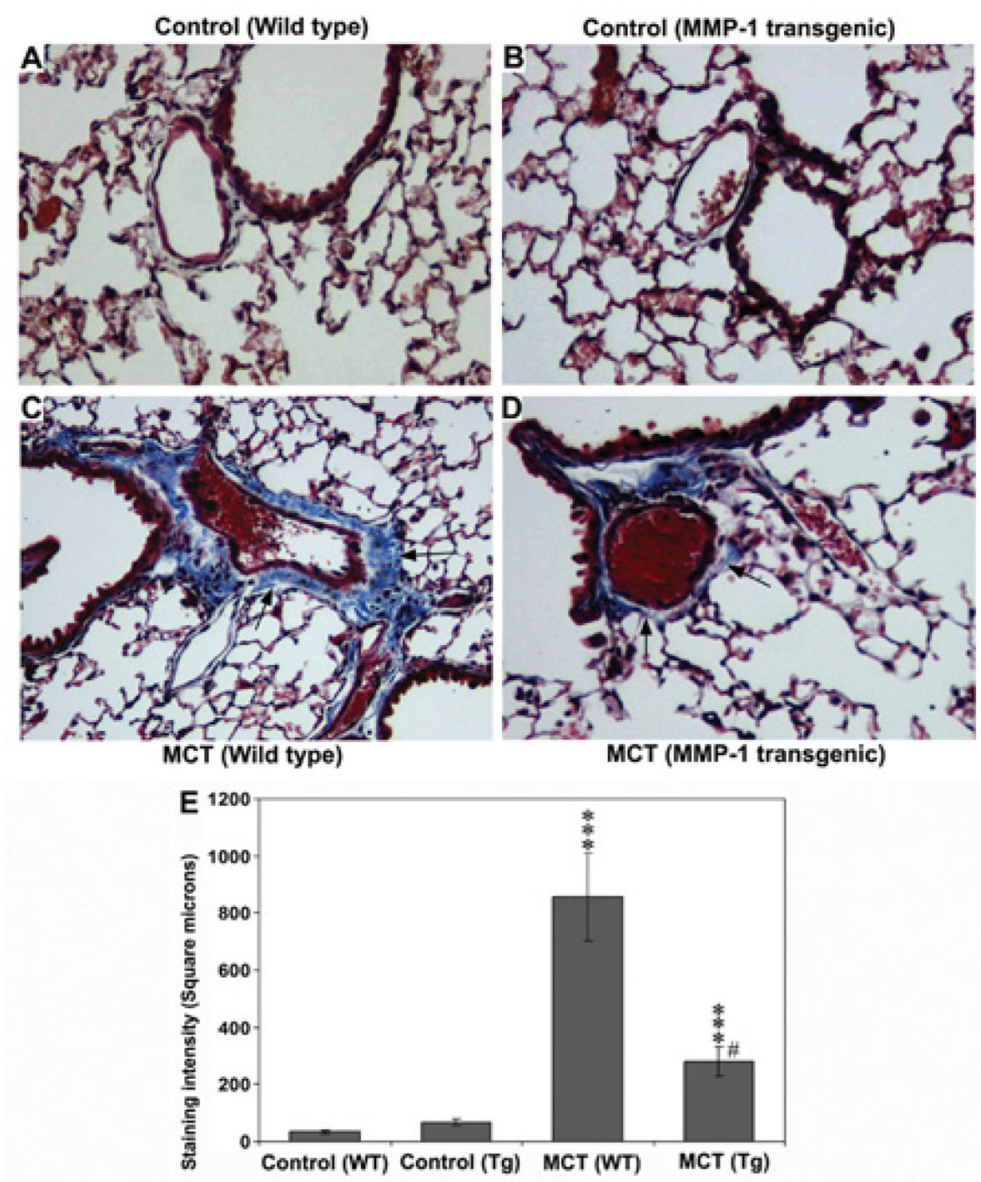

Figure 4. Masson's trichrome staining for collagen in the lung tissue of WT and MMP-1 transgenic mice after the induction of PAH using MCT

The results presented are representative of six animals in each group. (A) Normal lung WT mice (×200). (B) MMP-1 transgenic mice (×200). Absence of collagen deposition. (C) MCT-administered WT mice $(\times 100)$. Increase in perivascular fibrosis and deposition of mature collagen fibres stained as blue (arrow). There was constriction of pulmonary vessels. (D) MCT-administered MMP-1 transgenic mice $(\times 200)$. Only marginal deposition of collagen fibres in the perivascular area (arrow). (E) Quantitative evaluation of Masson's trichrome staining using Image-Pro discovery software. The results are the means \pm S.D. for ten randomly selected microscopic fields from six samples $\left({ }^{* * *} P<0.001\right.$ compared with the respective non-treated controls, and ${ }^{\#} P<0.001$ compared with MCT-treated WT). Tg, transgenic. 


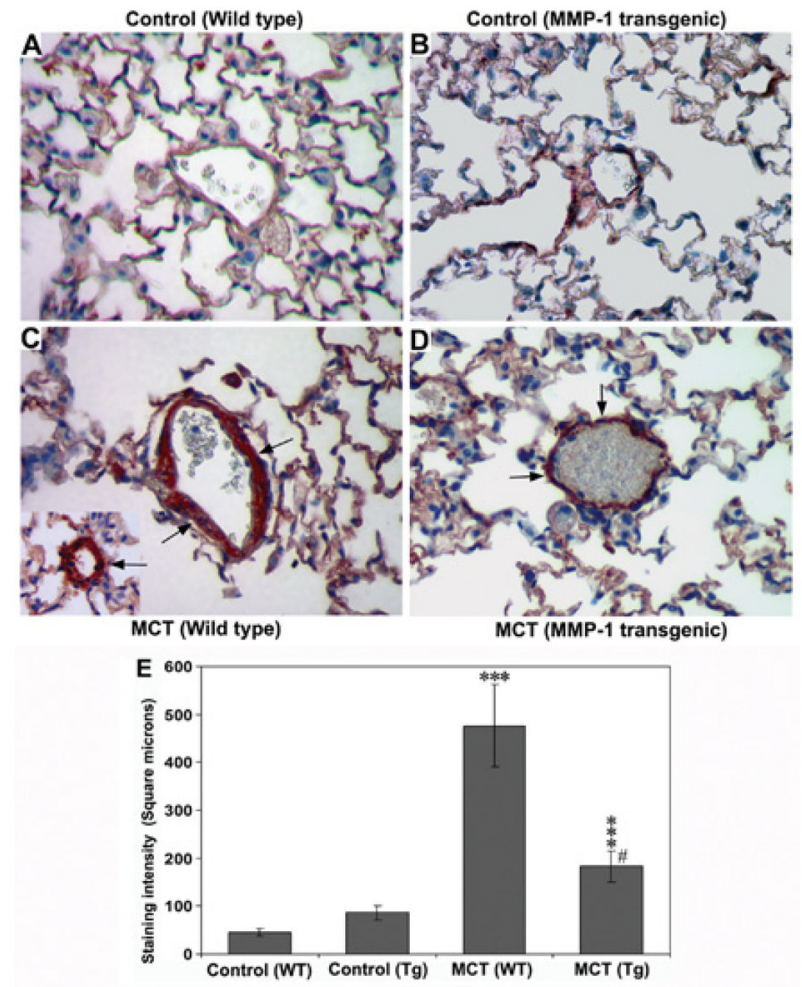

Figure 5. Immunohistochemical staining for a-SMA in the lung tissue of WT and MMP-1 transgenic mice after the induction of PAH using MCT

The results are representative of six animals in each group. (A) Normal lung WT mice (×200). (B) MMP-1 transgenic mice $(\times 200)$. Light staining of $a$-SMA in the pulmonary vessels. (C) WT mice (×200). MCT was administered in doses of $60 \mathrm{mg} / 100 \mathrm{~g}$ of body weight once a week for 8 consecutive weeks. Intense staining of $a$-SMA in the large pulmonary vessel, indicating extensive thickening of smooth muscle cell wall, medial hypertrophy and constriction of pulmonary vessels (arrows). Centre muscularization and marked constriction of a distal precapillary vessel (arrows). (D) MCT-administered MMP-1 transgenic mice $(\times 200)$. The thickening of the smooth muscle cell wall was markedly decreased compared with MCT-treated WT mice (arrows). The medial hypertrophy is minimal and no compromise of pulmonary vessel. (E) Quantitative representation of $a$ SMA staining. The results are the means \pm S.D. for ten randomly selected microscopic fields from six samples $\left({ }^{* * *} P<0.001\right.$ compared with the respective non-treated controls, and ${ }^{\#} P<$ 0.001 compared with MCT-treated WT). Tg, transgenic. 

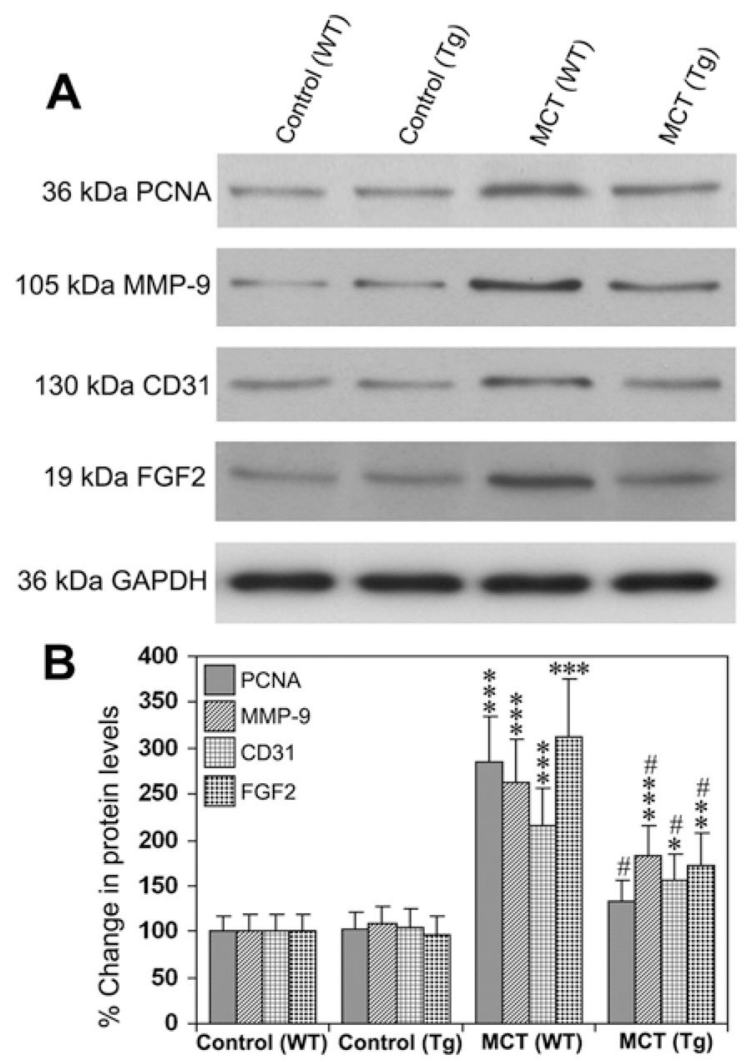

Figure 6. Western blot analysis of molecules involved in proliferation in WT and MMP-1 transgenic mice with and without the administration of MCT

(A) Representative Western blots for PCNA, MMP-9, CD31 and FGF2 in WT and MMP-1 transgenic mice with and without the administration of MCT. The PVDF membranes were reprobed for GAPDH content to demonstrate that equal amounts of proteins had been loaded in each lane. The results are representative of four independent experiments. (B) Quantitative evaluation of Western blots. The Western blot images were quantified using Gel-Pro analyzer software. The results are the means \pm S.D. for four independent experiments $\left({ }^{*} P<0.05,{ }^{* *} P<0.01\right.$ and ${ }^{* * *} P<0.001$ compared with the respective nontreated controls, and ${ }^{\#} P<0.001$ compared with the MCT-treated WT). Tg, transgenic. 